\title{
Unmixing river sediments for the elemental geochemistry of their source-regions
}

\author{
ALEX LIPP ${ }^{1}$, GARETH G ROBERTS ${ }^{1}$, CHARLES B \\ GOWING $^{2}$, ALEXANDER C WHITTAKER ${ }^{1}$ AND VICTORIA \\ M FERNANDES $^{1}$ \\ ${ }^{1}$ Imperial College London \\ ${ }^{2}$ British Geological Survey \\ Presenting Author: agl18@ic.ac.uk
}

The geochemistry of river sediments is frequently used to infer processes occurring upstream such as chemical weathering and erosion. However, a quantitative scheme to relate downstream sediment geochemistry to the geochemistry of source-regions is lacking. Here, we describe an inverse methodology to 'unmix' fluvial sediments from higher-order river channels to produce a geochemical map of their source-regions. To test our scheme we consider a case-study in the Cairngorms mountain range, UK. We gathered 67 fine-grained $(<150 \mu \mathrm{m})$ sediment samples from the five major drainage basins including both trunks and tributaries, over an area spanning $\sim 14,000 \mathrm{~km}^{2}$. The elemental geochemistry of the sampled sediments was then measured by ICP-MS following mixed-acid digestion. Our goal is to produce a geochemical map of the $\sim 14,000 \mathrm{~km}^{2}$ study area using the 67 sediment samples we gathered. We start with the assumption (supported by previous studies) that downstream sediment geochemistry in our region is a conservative mixture of the source-region (e.g. weathering happens in-situ, not in-transit). Hence, it is possible to predict the downstream sediment geochemistry as a mixture of the source-region geochemistry, given the structure of the drainage network. This structure can be extracted from digital elevation data. We are therefore able to transform a geochemical map of the source-region into a prediction of the composition of sediments downstream. For each analysed element, we then seek the source-region geochemistry that best fits the point observations downstream, i.e. the 67 sediment samples. This optimisation problem is solved using the Nelder-Mead algorithm. We seek spatially smooth solutions. Synthetic examples, where we attempt to reconstruct a known synthetic input, indicate that our scheme is able to recover longwavelength $(>20 \mathrm{~km})$ spatial geochemical patterns in the sourceregion. Predicted source-region compositions, generated by unmixing real data, are assessed using the independent G-BASE survey, which contains $\sim 8,000$ substrate samples across the studied region. This test shows that we can make meaningful predictions of major and trace elements including $\mathrm{Mg}, \mathrm{U}, \mathrm{K}, \mathrm{Sr}$, Ti. We propose that this scheme is a low-cost way to produce geochemical maps for use in environmental monitoring and geochemical exploration. 